\title{
Early Measures of Drought Tolerance in Four Grape Rootstocks
}

\author{
Kevin Fort and Joaquin Fraga \\ Department of Viticulture and Enology, University of California at Davis, 1 Shields Avenue, Davis, \\ CA 95616
}

Daniele Grossi

Department of Agricultural and Environmental Sciences, University of Milan, Via Celoria 2, 20133 Milan, Italy

\author{
M. Andrew Walker ${ }^{1}$ \\ Department of Viticulture and Enology, University of California, Davis, 1 Shields Avenue, Davis, \\ CA 95616
}

\begin{abstract}
AdDitional INDEX wORDs. dehydration resistance, grape, rootstock, breeding, viticulture, rhizotron
Abstract. Recent and severe droughts in major grape (Vitis)-growing regions of the United States and Australia underscore the importance of more efficient agricultural use of water. Grape rootstock breeding for increased drought tolerance could contribute to continued sustainable yields as fresh water supplies decline. Rhizotron containers were used in a greenhouse to investigate the predictive measures of drought tolerance in young grapevine rootstocks. Deeper rooting distributions were found for the drought-tolerant rootstocks '110R' (Vitis berlandieri $\times$ Vitis rupestris) and 'Ramsey' (Vitis champinii, a natural hybrid of Vitis candicans $\times V$. rupestris) as opposed to shallower distributions observed in the more drought-sensitive rootstocks ' $101-14 \mathrm{Mgt}$ ' (Vitis riparia $\times$ V. rupestris) and 'Riparia Gloire' $(V$. riparia). Production of new roots during a 6-day nonirrigated period declined $45 \%$ to $53 \%$ for 'Riparia Gloire' and '101-14Mgt', respectively, but showed no change in ' $110 \mathrm{R}$ ' and 'Ramsey'. Slow growth, a hallmark of abiotic stress tolerance, was evident in the drought-tolerant rootstocks in their relatively slow shoot growth before drought stress and their relatively slow new root growth during recovery, especially for 'Ramsey'. High stomatal conductance $\left(g_{S}\right)$ corresponded with drought tolerance and distinguished rootstocks best during the first 3 days of recovery, with a mean value for 'Ramsey' 2.7 times higher than '101-14Mgt'. Stomatal conductance during recovery may serve as the most efficient means of predicting drought tolerance capacity in a breeding program.
\end{abstract}

The use of rootstocks in viticulture was initiated in response to the widespread destruction of European vineyards after the inadvertent introduction of the grape phylloxera (Daktulosphaira vitifoliae) during the mid-19th century (Ordish, 1972). Rootstocks have since been developed for other traits that include nematode resistance, lime tolerance, salt tolerance, tolerance of saturated soil, and influence on scion vigor and fruit maturity (Galet, 1998; Pongrácz, 1983). Drought tolerance can also be included on this list, and the need for further improvement in rootstock-mediated drought tolerance is underscored by recent droughts in major grape-growing regions of Australia (National Climate Centre, 2010) and California (Di Liberto, 2015) and concomitant increasing urban demands on a limited freshwater supply (Fishman, 2012).

Variability in rootstock-mediated drought tolerance occurring among commercially available rootstocks has been documented. On the tolerant end of this spectrum are rootstocks derived from $V$. champinii. Such tolerance may be a characteristic of the

Received for publication 7 Sept. 2016. Accepted for publication 30 Nov. 2016. Funding from the California Grape Rootstock Improvement Commission, the Fruit Tree, Nut Tree and Grapevine Improvement Advisory Board, the California Table Grape Commission, the American Vineyard Foundation and a post-doctoral award from E\&J Gallo Winery is gratefully acknowledged. We thank Nira Azulai and Nina Romero for greenhouse assistance, Ray Fort for a rhizotron diagram, and Joshua Puckett and Michael Cunningham at Foundation Plant Services, University of California, Davis, for virus-tested plant material.

${ }^{1}$ Corresponding author. E-mail: awalker@ucdavis.edu. species: for example, an accession of $V$. champinii was shown to have the strongest drought tolerance of 17 Vitis species compared simultaneously (Padgett-Johnson et al., 2003). An example of a $V$. champinii rootstock that is generally regarded as drought tolerant is 'Ramsey', which is widely used in Australia (Walker and Clingeleffer, 2009). In multiple field trials, yield and pruning weight were highest when Vitis vinifera was grafted onto 'Ramsey' (Cirami and McCarthy, 1988; McCarthy et al., 1997; Stevens et al., 2008). In the McCarthy et al. (1997) study, 'Ramsey' had the highest yield in both a dry-farmed treatment and an irrigated control, and similar results were reported in Stevens et al. (2008). These results imply that the rank order of performance under unstressed conditions could be predictive for drought tolerance capacity, a principle supported by the correlation of pruning weight rank order (and to a lesser degree, yield) of five grape rootstocks over a wide range of midday leaf water potentials, induced using increasingly restrictive irrigation regimes (Williams, 2010). This principle was also true for the rootstock 'Richter 110' (hereafter '110R'), which was included in the abovementioned studies and is also considered to be drought tolerant (Keller, 2015). In these studies, '110R' produced lower yields and pruning weight relative to 'Ramsey' under both control and water-stressed conditions (McCarthy et al., 1997; Stevens et al., 2008), and also in field trials not specifically targeting performance under drought (Cirami and McCarthy, 1988).

On the drought-sensitive end of the spectrum are rootstocks derived from $V$. riparia, and two examples are $V$. riparia 'Riparia Gloire de Montpellier' (hereafter 'Riparia') and a rootstock 
derived from V. riparia, 'Millardet et de Grasset 101-14' (hereafter '101-14Mgt'). Dry and Coombe (2005) note that $V$. riparia-based rootstocks are in general regarded as drought sensitive, and that both 'Riparia' and '101-14Mgt' were recommended against in a drought-prone region as early as 1935 (de Castella). Pouget and Delas (1989) rank 'Riparia' and '101-14Mgt' as low in drought resistance and ' $110 \mathrm{R}$ ' as high, and a literature review of rootstock surveys by Ollat et al. (2015) ranked 'Riparia' as low, '101-14Mgt' as very low to medium, '110R' as high to very high, and 'Ramsey' as medium to very high in water stress adaptation.

Despite these cited studies, the ranking of multiple rootstocks for yield and pruning weight using common garden style field trials produces notoriously inconsistent results. Two of many examples include Lambert et al. (2008) who observed an expected 'Ramsey' > '110R' > '101-14Mgt' rank ordering of pruning weight and yield in some sites, but not others, and an instance where the expected 'Ramsey' > '101-14Mgt' rank order for pruning weight was inverted (Southey, 1992). The environmental influences that likely underlie the sometimes-observed confounding of yield and biomass as measures of drought tolerance might be averted in part if surveys were to be performed in the greater environmental uniformity of a greenhouse with a pest- and diseasefree and even-textured soil media, as were performed by Carbonneau (1985) and Natali et al. (1985). In the present study, a rhizotron container system was used with the abovementioned rootstocks 'Ramsey', '110R', 'Riparia', and '101-14Mgt', and sought to expand on these earlier greenhouse-based assays. Questions in this study specifically addressed 1) the degree to which strictly anatomical characterizations of root architecture and shoot biomass in unstressed young vines could predict drought-tolerance capacity, 2) the degree to which root and shoot growth responses of young vines to a single cycle of drought stress and recovery could predict drought-tolerance capacity, 3 ) the degree to which and in what time period (i.e., stress vs. recovery) $g_{\mathrm{S}}$ of young vines could predict drought-tolerance capacity, and 4) the degree to which measures of young vines at harvest (following drought stress and recovery) could predict drought-tolerance capacity. Elucidation of these questions could provide insights into the genetically based variability of whole plant level responses to drought stress and recovery, and optimize the breeding of Vitis rootstocks for improved drought tolerance.

\section{Materials and Methods}

Rhizotron CONSTRUCTION, PLANT MATERIALS, AND PROPAGATION. Rhizotrons were constructed according to James et al. (1985) and consisted of a $61.0 \times 30.5-\mathrm{cm}$ acrylic glass face with a plywood backing of equal dimensions (Fig. 1). The plywood backing and acrylic glass face were aligned and separated by vinyl tubing of 19-mm o.d., creating a soil media depth of $\approx 51 \mathrm{~cm}$ and average width of $\approx 21 \mathrm{~cm}$. Acrylic glass and plywood were fastened with bolts along the rhizotron perimeter. A hole was drilled through the bottom of the vinyl tubing to allow for water drainage. Rhizotrons were filled with a soil media composed of $40 \%(\mathrm{v} / \mathrm{v})$ washed sand, $20 \%(\mathrm{v} / \mathrm{v})$ sphagnum peatmoss, $20 \%(\mathrm{v} / \mathrm{v})$ redwood compost, and $20 \%(\mathrm{v} / \mathrm{v})$ pumice rock with the following amendments: $148 \mathrm{~g} \cdot \mathrm{m}^{-3}$ potassium nitrate, $148 \mathrm{~g} \cdot \mathrm{m}^{-3}$ potassium sulfate, $1.48 \mathrm{~kg} \cdot \mathrm{m}^{-3}$

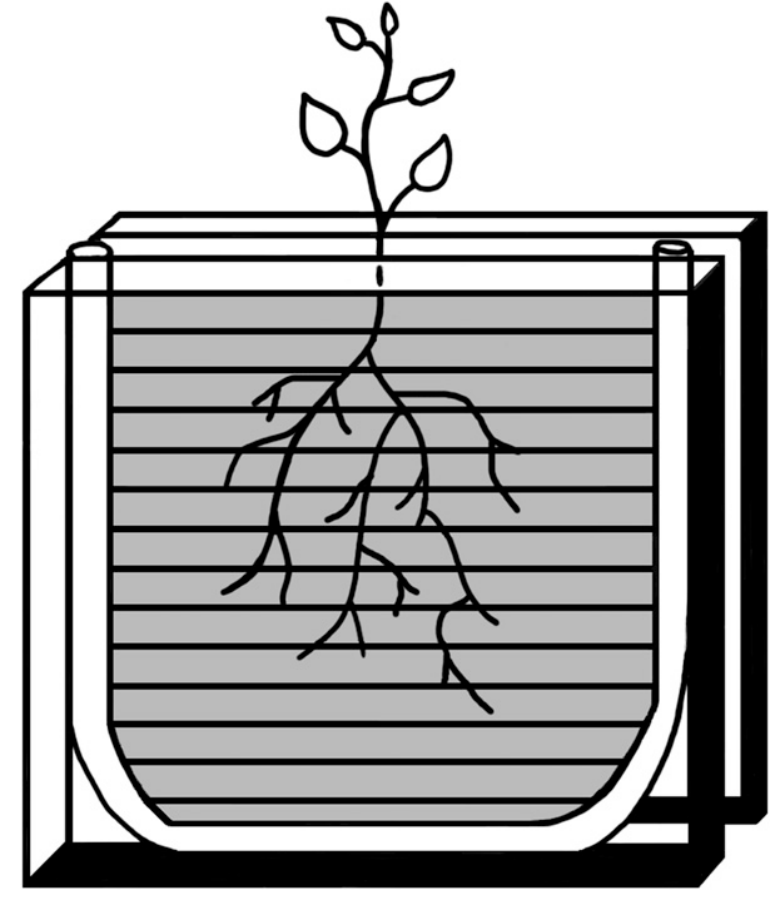

Fig. 1. Diagram of rhizotron containers used in the present study. Acrylic glass face and plywood backing were separated by vinyl tubing, creating a narrow chamber that was filled with soil media. Grape roots growing against the acrylic glass were scored as intercepts on an overlaid grid of horizontal lines spaced $2 \mathrm{~cm}$ apart.

single superphosphate, $4.45 \mathrm{~kg} \cdot \mathrm{m}^{-3}$ dolomite lime, and $1.48 \mathrm{~kg} \cdot \mathrm{m}^{-3}$ calcium carbonate lime.

Dormant cuttings of 'Ramsey', '110R', 'Riparia', and '101$14 \mathrm{Mgt}$ ' were collected on $28 \mathrm{Feb} .2013$ from vines maintained at the University of California, Davis, and stored at $\approx 2.2{ }^{\circ} \mathrm{C}$. Noting that different wine grape cultivars are known to exhibit differential vigor (Kerridge and Antcliff, 1999) and might therefore variably affect rootstock traits, this study focused on traits measured while using the single scion cultivar $V$. vinifera Merlot and is not intended to compare scion-rootstock interactions. Scion wood of 'Merlot' was grafted onto the four rootstocks on 27 Mar. 2013, callused at $27{ }^{\circ} \mathrm{C}$ in moistened 50:50 perlite/vermiculite, and planted in equal parts perlite/ vermiculite/peat with $27{ }^{\circ} \mathrm{C}$ bottom heat on 4 Apr. 2013. Eight vines of each rootstock type were selected for uniformity and planted individually into eight separate rhizotrons on 1 May 2013; given four rootstock types, 32 total rhizotrons were used in this experiment. Measurements of roots, described below, commenced 1 week later and therefore 8 May 2013 was designated week 1 , day 1 . At the time of planting, weight of the rhizotron, dry soil media, and plant weight was recorded using an electronic scale with $60-\mathrm{kg}$ capacity and 5-g resolution (HW-60KGL; A\&D Co., Elk Grove, IL). Rhizotrons were watered to saturation a second time following sunset on the day of planting and the total weight was recorded the subsequent morning before sunrise. Water retained averaged $653 \mathrm{~mL}$ and did not differ by genotype $(P<0.65)$. All plants were established in a greenhouse using daily irrigations for 4 weeks with a modified Hoagland's solution. The greenhouse was located at the University of California, Davis with temperatures maintained between nighttime lows of $23{ }^{\circ} \mathrm{C}$ to daytime highs of $35^{\circ} \mathrm{C}$. 
EXPERIMENTAL DESIGN AND APPLICATION OF DROUGHT AND RECOVERY TREATMENTS. Four individuals of each grafted rootstock were used for the drought treatment and were arranged within a randomized complete block design with four blocks, each block containing one individual of each rootstock type. The remaining four individuals of each rootstock type were used as a daily-irrigated control. Rhizotrons were rested against each other at a $35^{\circ}$ angle from vertical with the acrylic glass facing downward, allowing the visualization of roots growing along the inner face of the window while still permitting downward and lateral growth. The row of rhizotrons was supported on both ends with cinder blocks. The stacked arrangement, together with aluminum foil wrapped around the entire row of rhizotrons, helped to minimize light penetration into the root zone and to suppress algal growth on the inner face of the acrylic glass. Plant-to-plant shading was minimal due to the relatively small canopies of the young plants and the lack of perfect symmetry of planting; nevertheless, canopies were repositioned as necessary when interference occurred. Plants assigned to the drought treatment received their final establishment-period irrigation on week 4, day 1 at 2030 HR and received no subsequent irrigation until week 5, day 1 at 0900 HR. Recovery-period irrigations were applied daily at 0900 HR through week 5, day 7. From week 4, day 2 to week 4, day 5 control plants were irrigated daily at $0900 \mathrm{HR}$ with a volume calculated to restore $75 \%$ of pot capacity, gravimetrically determined. On week 4, day 6 and thereafter, irrigations were made to restore $100 \%$ of pot capacity to ensure a maximal separation of stress and nonstress responses. Recovery irrigations to drought treatment plants that began on week 5 , day 1 were also made to restore $100 \%$ of pot capacity. To minimize evaporative loss from the soil surface, household plastic wrap was used to cover the soil surface except within $1 \mathrm{~cm}$ of the shoot base to permit some gas exchange.

Measurements. Only nondestructive measurements were taken before harvest. This strategy was designed to prevent physiologically significant reductions in leaf area from the relatively small canopies that could otherwise have occurred if leaves had been removed each day to measure leaf or stem water potential. Stomatal conductance was measured daily from the abaxial side of the leaf using a leaf porometer (SC-1; Decagon Devices, Pullman, WA) at solar noon $\pm 1 \mathrm{~h}$ beginning week 4 , day 2 . Two unshaded, fully expanded young leaves were measured for each individual. It is noted that on week 5 , day 1 , the first day of recovery, only $\approx 3 \mathrm{~h}$ had passed since the time of irrigation. Root development was tracked by overlaying acetate sheets onto the acrylic glass face and tracing new roots with different colored markers each week. Root tracings were taken at weekly intervals beginning on week 1 , day 1. An example of the appearance of root tracings before the onset of drought on week 4, day 1, is shown in Fig. 2. A grid of horizontal lines spaced $2 \mathrm{~cm}$ apart was used to quantify root intersections with depth (Fig. 1). Following the tabulation of root intersections along each horizontal line, root intersections were then categorized as either shallow or deeply angled. Shallow-angled roots were defined as being closer to parallel to the soil media surface and ranging from $0^{\circ}$ (i.e., parallel with the surface) to $30^{\circ}$ of downward departure from parallel. Deeply angled roots ranged from $31^{\circ}$ to $90^{\circ}$ (i.e., $90^{\circ}$ being perpendicular to the surface). Although the distinction of $30^{\circ}$ as a threshold for categorization was subjective, it was determined from an informal sampling of root angle measurements before

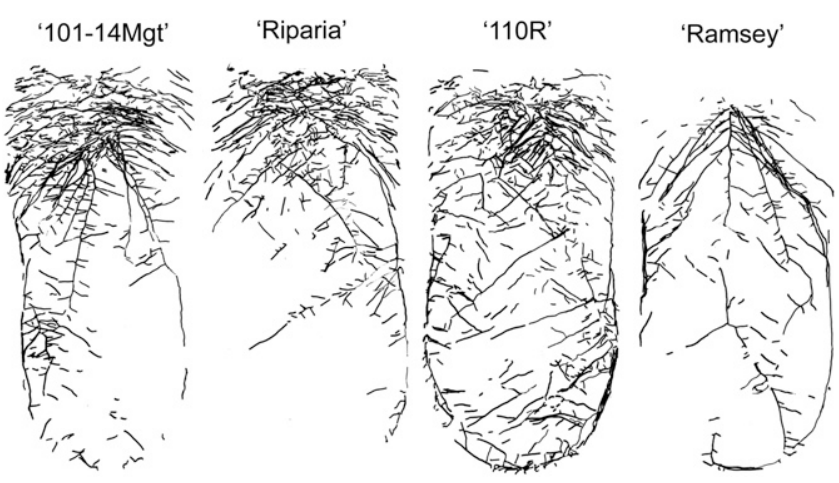

Fig. 2. Examples of grape rootstock roots growing along the transparent inner face of rhizotron containers used in the present study. Images are grayscale derivations of color-coded tracings obtained by overlaying acetate sheets onto the acrylic glass face once per week. Images are from daily-irrigated vines at week 4 , day 1 , where week 1 , day 1 was the first day of root measurements; '101-14Mgt' = 'Millardet et de Grasset 101-14', 'Riparia' = 'Riparia Gloire de Montpellier', and '110R' = 'Richter 110'.

the formal scoring that indicated a relative abundance of shallow-angled roots in the $0^{\circ}$ to $30^{\circ}$ range for the droughtsusceptible rootstocks '101-14Mgt' and 'Riparia'. Stem lengths were measured once on week 2 , day 6 , then on alternate days beginning on week 4, day 2 . Transpired water was measured gravimetrically each morning before irrigation. Following final nondestructive measurements, leaves were harvested and leaf area was measured on an area meter (LI-3100; LI-COR Biosciences, Lincoln, NE). Upper and lower halves of the soil profile were separated. Harvested leaves, the remainder of the shoots, and washed roots were dried to a constant mass at $67{ }^{\circ} \mathrm{C}$ and weighed.

STEM LengthS FROM SECOND SEASON OF PROPAGATION. To test the repeatability of differences in total stem length that were observed during establishment in 2013 (reported in the Results), a second set of vines was propagated in 2014 using identical propagation methods, but with $5 \times 5 \times 20-\mathrm{cm}$ containers. This experimental set used a $V$. vinifera ' $\mathrm{Cabernet}$ Sauvignon' scion, and the resulting rooted vines were planted in equal parts perlite/vermiculite/peat on $21 \mathrm{Feb}$. 2014. On 5 Apr. 2014, stem lengths were measured as in 2013 following $43 \mathrm{~d}$ of growth with daily irrigation.

Statistical ANALYSES. Means and SDS were generated in Microsoft Excel (Microsoft, Seattle, WA). Student's $t$ tests, regressions, Pearson's product-moment correlations, analyses of variance, and repeated measures analyses were performed in SigmaPlot (version 11.0; Systat Software, Chicago, IL). Post hoc mean separations used a Holm-Sídák multiple comparison test also using SigmaPlot (version 11.0). Student's $t$ tests with heteroscedastic distributions were alternatively tested with a Mann-Whitney rank-sum test.

\section{Results}

UNSTRESSED DIFFERENCES IN ROOT AND SHOOT DEVELOPMENT. On the final day of the daily watered establishment period, genotype differences in root distribution with depth were visually apparent (Fig. 2). Using root distribution curves (Fig. $3 \mathrm{~A}$ ) and an analysis of variance for the depth at which $90 \%$ of root intersections were accounted for (Fig. 3B), a rank ordering of genotypes with increasingly deep rooting profiles was made 

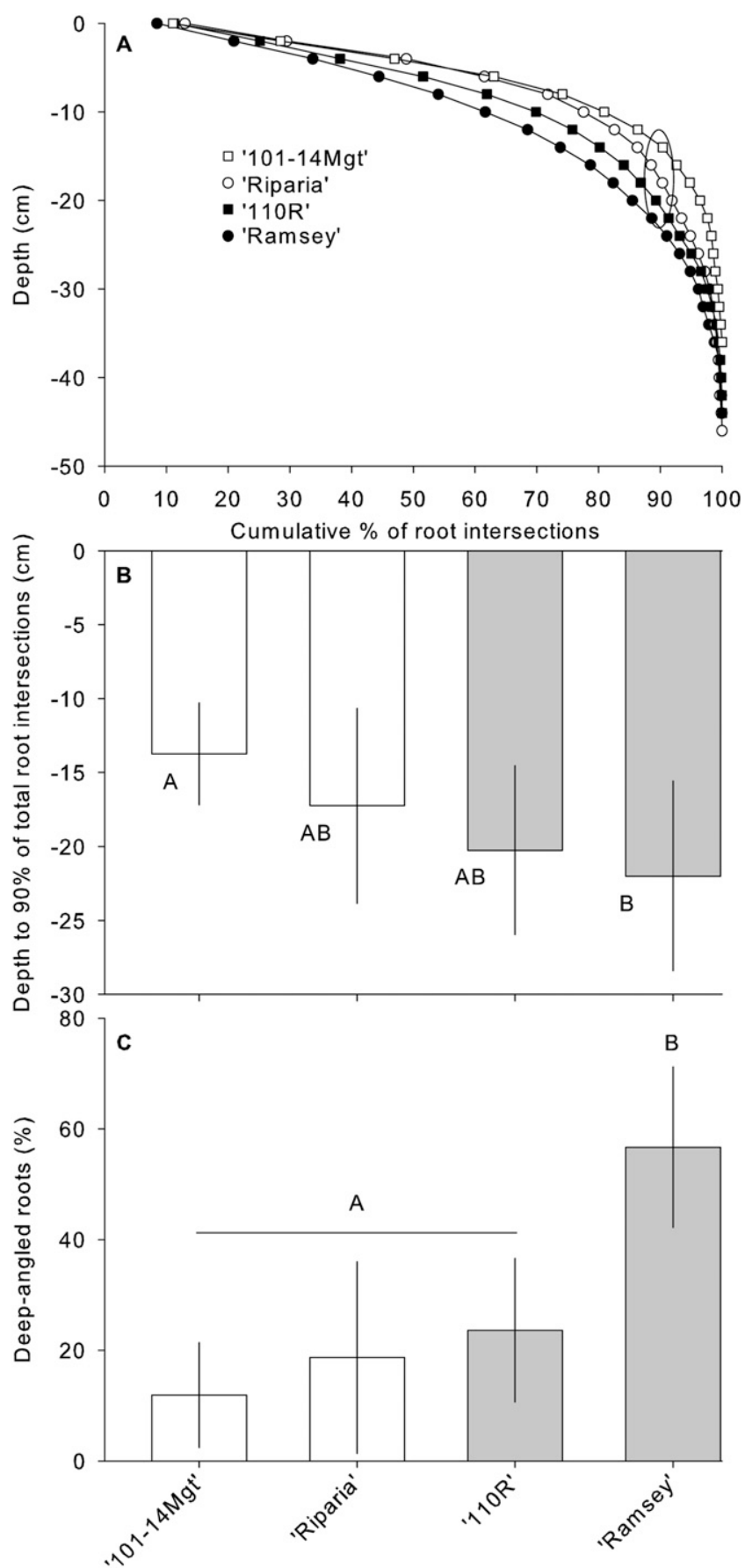

Fig. 3. Descriptive measures of grape rootstock roots growing along the transparent inner face of rhizotron containers used in the present study. Data are from daily-irrigated vines at week 4, day 1 , where week 1 , day 1 was the first day of root measurements; '101-14Mgt' = 'Millardet et de Grasset 101-14', 'Riparia' = 'Riparia Gloire de Montpellier', and '110R' = 'Richter 110'. Putative drought-resistant genotypes were represented with filled symbols and gray columns. (A) Cumulative intersections of roots by soil depth using a grid of horizontal lines overlaid onto the rhizotron face. Depth to $90 \%$ of total intersections is highlighted with an oval. (B) Depth to $90 \%$ of total intersections with associated variation and post hoc mean separation. (C) Percentage of root intersections with a deep rooting angle $\left(>30^{\circ}\right.$ relative to the $0^{\circ}$ soil surface). Error bars are \pm 1 SD. Letters indicate post hoc mean separation categories.

as follows: '101-14Mgt' (shallowest distribution) < 'Riparia' < ' $110 \mathrm{R}$ ' < 'Ramsey' (deepest distribution). The percentage of deeply angled roots by genotype followed the same rank order as the cumulative root distributions with depth, but the $57 \%$ of deeply angled roots observed in 'Ramsey' was 3.1 times higher than the mean of '101-14Mgt', 'Riparia' and '110R' (Fig. 3C). Total number of root intersections, an index for root length described in the Materials and Methods, differed by genotype $(P<0.004)$ but did not correspond in rank order to root depth distributions. Mean number of root intersections (with mean separation categories) were as follows: 'Ramsey' = 90.5 (A), 'Riparia' = 120.8 (AB), '101-14Mgt' = $147.4(\mathrm{AB})$, and ' $110 \mathrm{R}$ ' = $180.0(\mathrm{~B})$.

Interestingly, 'Ramsey' had both the deepest rooting distribution and the least amount of stem length development: $51 \%$ less than the mean of '101-14Mgt', 'Riparia', and '110R' (Fig. 4A). Conversely, '101-14Mgt' had both the shallowest distribution of roots (Fig. 3A and B) and the highest mean stem length (Fig. 4A). Measurements of stem length on a grafted 'Cabernet Sauvignon' scion under unstressed conditions were taken a second time in 2014 with replication that was 2.5 to 6.4 times higher than the eight replicates per genotype presented in Fig. 4A. In this second test, the rank order of increasing mean stem length was 'Ramsey' (least stem length) < '110R' < 'Riparia' < '101-14Mgt' (greatest stem length), with '110R' and 'Riparia' equivalent and 'Ramsey' with $56 \%$ less total stem length than '101-14Mgt' (Fig. 4B).

NEW ROOT PRODUCTION: DROUGHT AND RECOVERY RESPONSES. A time course of new root production is presented in Fig. 5. Notable before the drought treatment is the rapid increase in new roots produced in the first week by '101-14Mgt' (Fig. 5A) in contrast to the relatively slow pace of root production in 'Ramsey' (Fig. 5D), with 'Riparia' and '110R' intermediate between these extremes (Fig. 5B and $\mathrm{C}$ ). Using repeated measures analyses, no changes were observed in new root production for daily watered controls during the drought period or during the recovery period (Fig. 5A-D). For drought-treated plants during the drought period, a 53\% decline was seen for '101-14Mgt', a 45\% decline for 'Riparia', but no change for ' $110 \mathrm{R}$ ' and 'Ramsey'. In the recovery period, new root intersections for drought-treated plants increased 6.7 times for '101-14Mgt', 3.3 and 3.0 times for 'Riparia' and '110R', respectively, and 1.3 times for 'Ramsey' (but was not significant for 'Ramsey').

SHOOT GROWTH AND $G_{S}$ : DROUGHT AND RECOVERY RESPONSES. A time course of total stem length is presented in Fig. 6. A repeated measures analysis of stem length over the drought period showed an increase in the controls but a lack of growth for drought-treated plants. However, the variability in stem length was high enough that control and drought-treated means were not separable on week 5 , day 1 nor on week 5 , day 7 for any genotype using $t$ tests $(P=0.120$ to 0.514$)$.

A 13-d time course of $g_{\mathrm{S}}$ is presented in Fig. 7, beginning with the first day of the drought treatment. An unambiguous separation of $g_{\mathrm{S}}$ values between drought-treated and control plants was observed on week 4, day 5 for '101-14Mgt', 'Riparia', and '110R' (Fig. 7A-C), and on week 4, day 6 for 'Ramsey' (Fig. 7D). By week 4, day 7, mean $g_{\mathrm{S}}$ for droughttreated plants ranged from 61 to $122 \mathrm{mmol} \cdot \mathrm{m}^{-2} \cdot \mathrm{s}^{-1}$, a level consistent with severe water stress in studies that maintained very low soil water content in potted plants (Kim et al., 2012; Nemali and van Iersel, 2008). There was little change in midday $g_{\mathrm{S}}$ following the first recovery irrigation at $0900 \mathrm{HR}$ on week 5, day 1 , but a distinct increase was observed for all genotypes on week 5 , day 2 at midday, $\approx 27 \mathrm{~h}$ postirrigation 

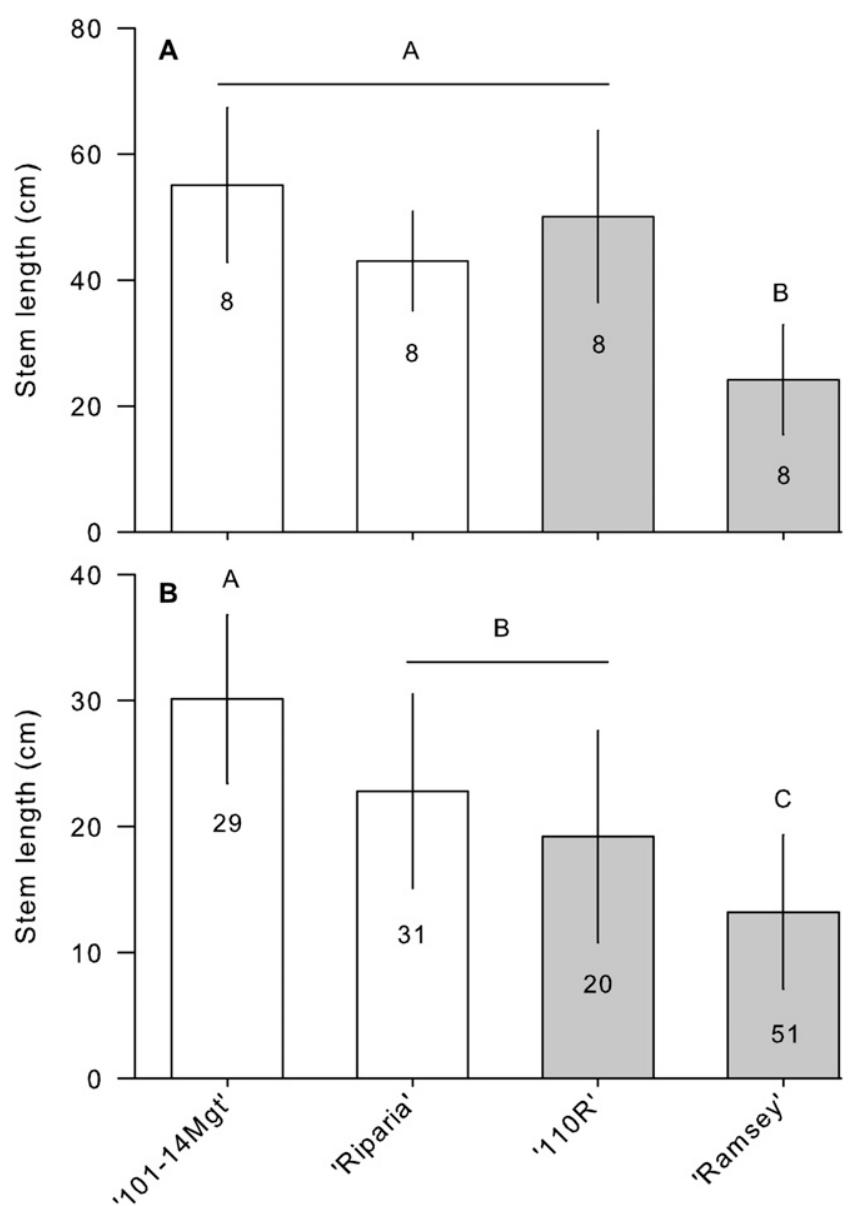

Fig. 4. Total stem length of grape scions from two independent propagations. Putative drought-resistant rootstocks were noted graphically using gray columns. (A) Total stem lengths of Vitis vinifera 'Merlot' scions grafted onto four rootstocks and grown in rhizotron containers in 2013. Measurements taken at week 4 , day 2 , where week 1 , day 1 was the first day of root measurements in the present experiment. (B) Total stem lengths of $V$. vinifera 'Cabernet Sauvignon' scions grafted onto four rootstocks and grown in $5 \times 5 \times$ 20 -cm containers. Plants were obtained from an independent propagation in 2014, and measurements were taken at $43 \mathrm{~d}$ of growth following planting. For both (A) and (B), replicate number for each rootstock genotype is noted within the corresponding column. Error bars are \pm 1 SD. Letters indicate post hoc mean separation categories; '101-14Mgt' = 'Millardet et de Grasset 101-14', 'Riparia' = 'Riparia Gloire de Montpellier', and '110R' = 'Richter 110'.

(Fig. 7). A further examination of $g_{\mathrm{S}}$ was conducted by dividing the time course into three periods, and pooling the data within these periods: 1) week 4 , day 6 to week 5 , day 1 , the period of unambiguous drought stress for all genotypes (Fig. 8A);2) week 5 , day 2 to week 5 , day 4 , the period of initial recovery from drought stress (Fig. 8B); and 3) week 5, day 2 to week 5, day 7 , the full recovery period measured in the experiment (Fig. 8C). In Fig. 8A-C, only the $g_{\mathrm{S}}$ for drought-treated plants is compared. In Fig. 8D, comparisons are made between genotypes for the difference of control and drought-treated $g_{\mathrm{S}}$ measurements within genotype and during the initial recovery period. A comparison of the three periods revealed a consistent rank order of genotypes parallel to that observed in rooting depth, with '101-14Mgt' having the lowest $g_{\mathrm{S}}$, intermediate values for 'Riparia' and '110R', and the highest values for 'Ramsey' (Fig. 8A-C). Only the initial recovery period yielded differences $[P<0.022$ (Fig. 8B)]. The average difference between

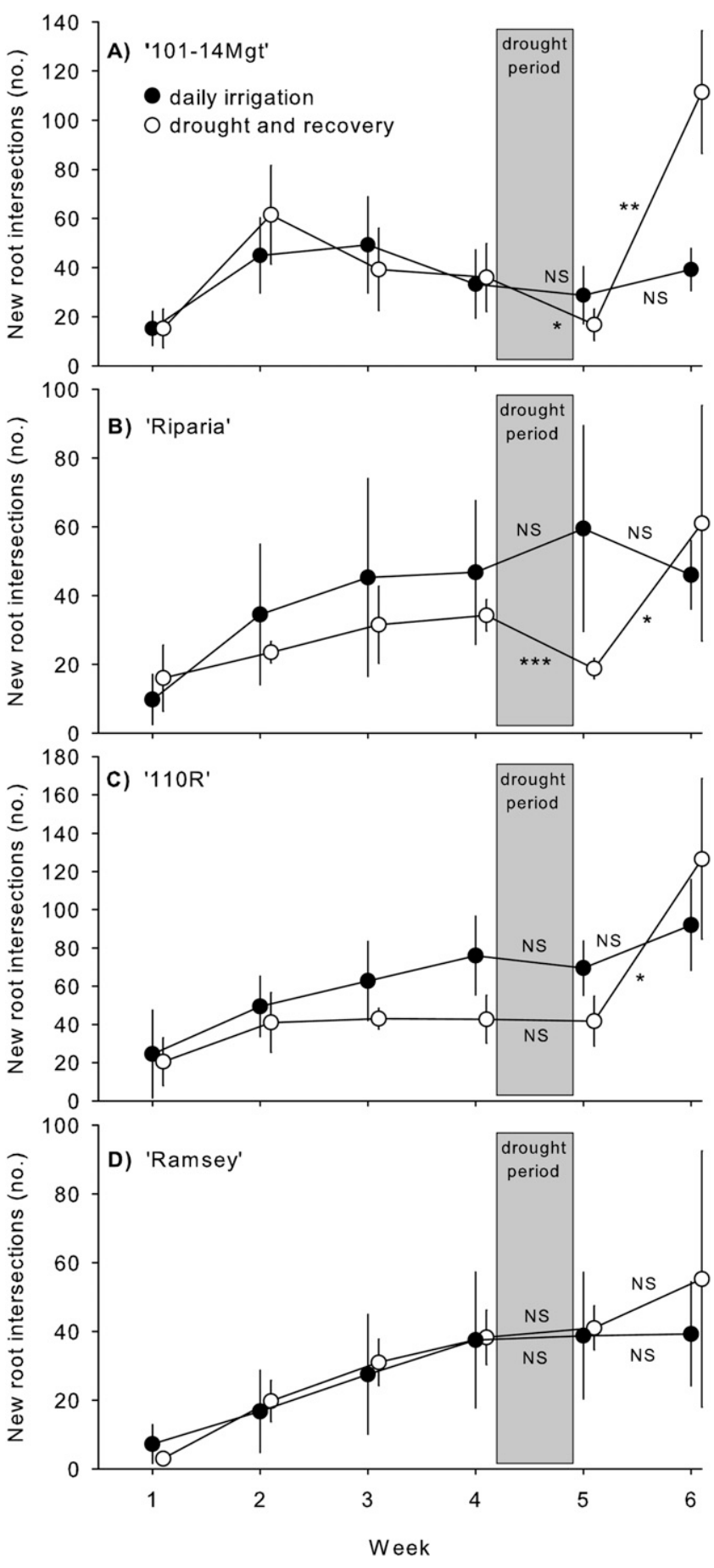

Fig. 5. A 6-week time course of new root growth by grape rootstock roots growing along the transparent inner face of rhizotron containers. Data are new root intersections with an overlaid grid of horizontal lines. Shaded rectangle symbolizes a drought period for treatment plants. Measurements were taken on the first day of each indicated week. Error bars are $\pm 1 \mathrm{SD}$. Change in the number of intersections during the drought and recovery periods was indicated as $* P<0.05,{ }^{* *} P<0.01,{ }^{* * *} P<0.001$, and $\mathrm{NS}=$ not significant; '101-14Mgt' = 'Millardet et de Grasset 101-14', 'Riparia' = 'Riparia Gloire de Montpellier', and '110R' = 'Richter 110'.

control and drought-treated values during the initial recovery period (Fig. 8D) was also distinguishable between genotypes $(P<0.011)$, as was the full $6-\mathrm{d}$ recovery period, albeit less distinctly $[P<0.045$ (data not shown)]. 

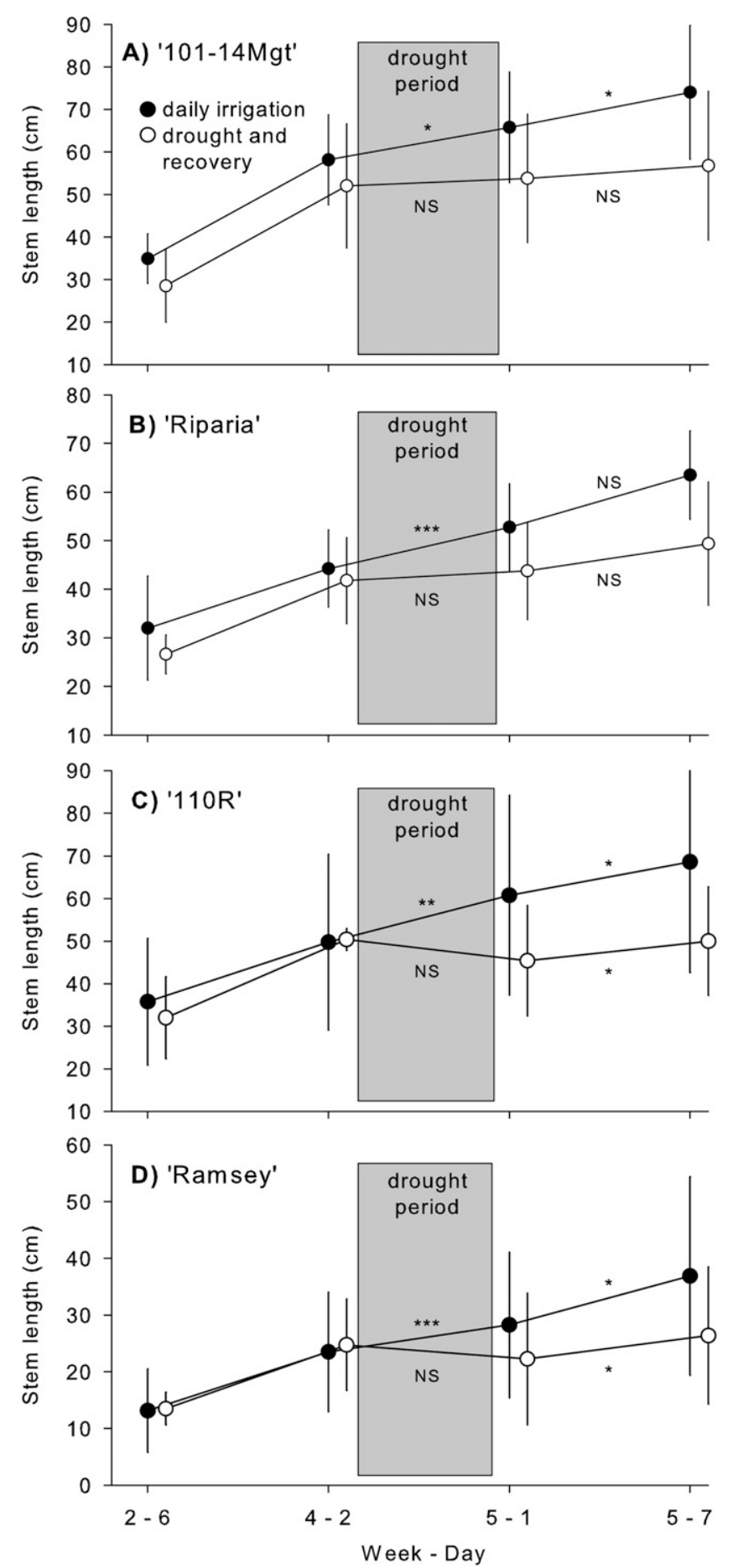

Fig. 6. A 4-week time course of total stem length of scions of Vitis vinifera 'Merlot' grafted onto four rootstocks and grown in rhizotron containers. Shaded rectangle symbolizes a drought period for treatment plants. Measurements were taken at the week and day indicated, where week 1, day 1 was the first day of root measurements in the present experiment. Error bars are \pm 1 SD. Change in stem length during the drought and recovery periods was indicated as $* P<0.05, * * P<0.01, * * * P<0.001$, and $\mathrm{NS}=$ not significant; '101-14Mgt' = 'Millardet et de Grasset 101-14', 'Riparia' = 'Riparia Gloire de Montpellier', and '110R' = 'Richter 110'.
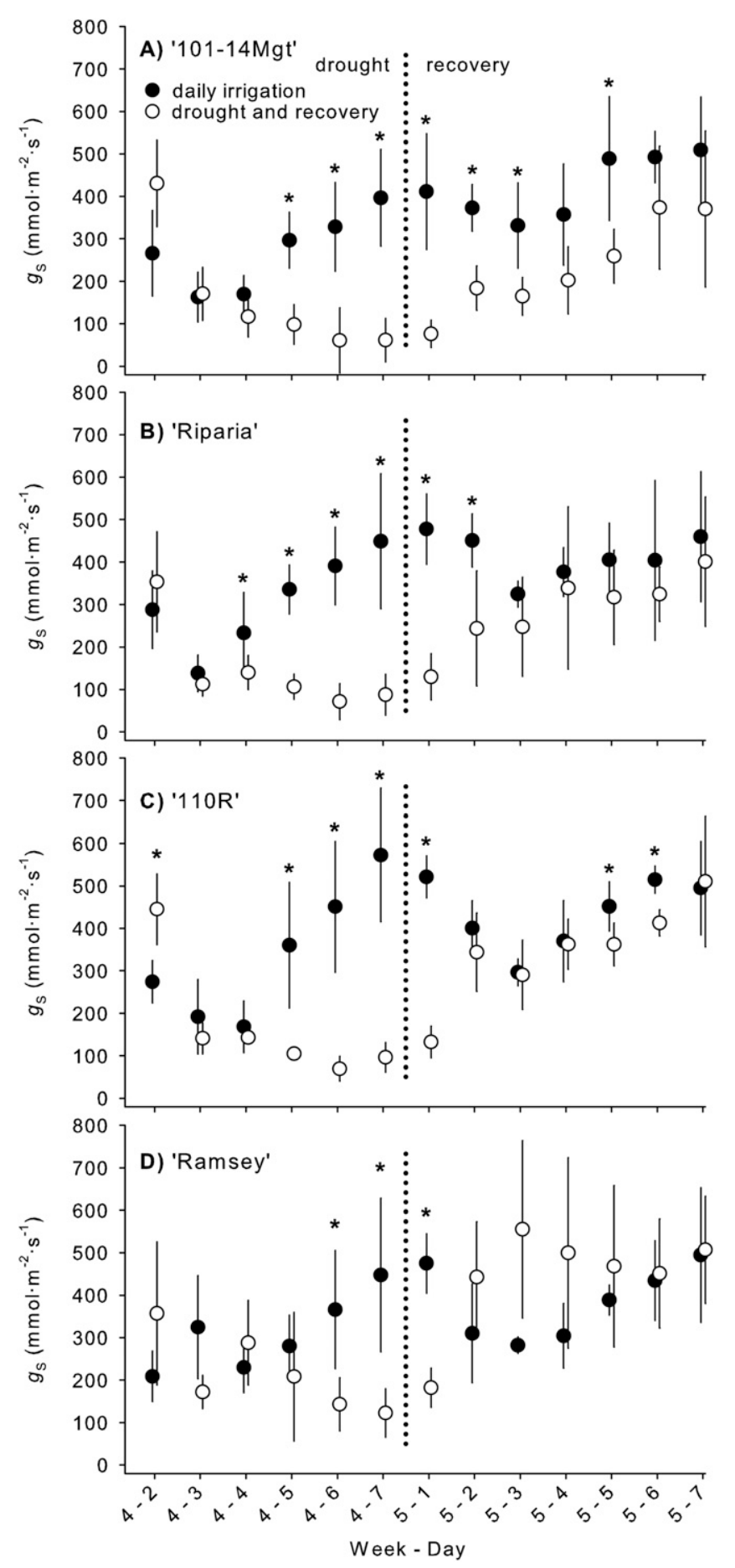

Fig. 7. A 13-d time course of midday stomatal conductance $\left(g_{\mathrm{S}}\right)$ of scions of Vitis vinifera 'Merlot' grafted onto four rootstocks and grown in rhizotron containers. Vertical dotted lines separate 6-d drought period for treated plants from 7-d daily-irrigated recovery period. Measurements were taken at the week and day indicated, where week 1, day 1 was the first day of root measurements in the present experiment. Irrigations were performed daily at $0900 \mathrm{HR}$; therefore, data for week 5 , day 1 was collected $\approx 3 \mathrm{~h}$ postirrigation. Error bars are $\pm 1 \mathrm{SD}$. Asterisks indicate differences $(\alpha=$ 0.05 ) between treatment and controls in a $t$ test; ' $101-14 \mathrm{Mgt}$ ' = 'Millardet et de Grasset 101-14', 'Riparia' = 'Riparia Gloire de Montpellier', and ' $110 \mathrm{R}$ ' = 'Richter 110 '. 

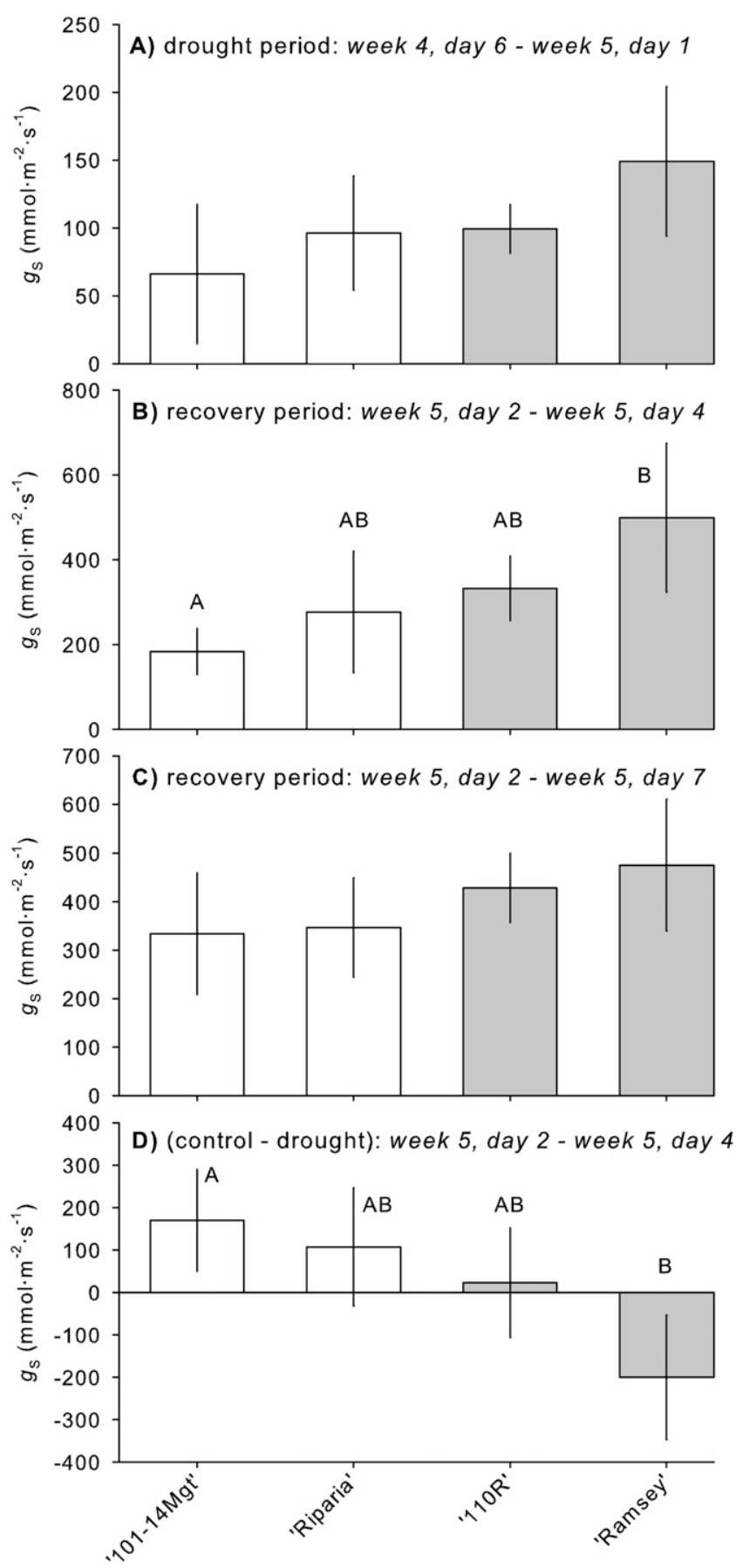

Fig. 8. Means of pooled, midday stomatal conductance $\left(g_{\mathrm{S}}\right)$ data from three periods for scions of Vitis vinifera 'Merlot' grafted onto four rootstocks and grown in rhizotron containers. Putative drought-resistant rootstocks were noted graphically using gray columns. Measurements were taken for the range of weeks and days indicated, where week 1, day 1 was the first day of root measurements in the present experiment. (A) $g_{\mathrm{S}}$ for droughttreated plants during the three final days of drought treatment. (B) $g_{\mathrm{S}}$ for drought-treated plants during the first half of the recovery period. (C) $g_{S}$ for drought-treated plants during the full $6 \mathrm{~d}$ of recovery. (D) $g_{\mathrm{S}}$ of control minus drought treatment values during the first half of the recovery period. Error bars are $\pm 1 \mathrm{SD}$. Post hoc mean separation categories are provided when an analysis of variance was significant at $\alpha=0.05$; '101-14Mgt' $=$ 'Millardet et de Grasset 101-14', 'Riparia' = 'Riparia Gloire de Montpellier', and ' $110 \mathrm{R}$ ' = 'Richter 110'.
Root:SHOOT RATIOS. A nondestructive index for root:shoot $(\mathrm{R}: \mathrm{S})$ biomass ratio was used based on cumulative root intersections as a correlate for root biomass and stem length as a correlate for shoot biomass. On week 4, day 1 to week 6, day 1 , mean R:S was higher for '110R' and 'Ramsey' compared with '101-14Mgt' and 'Riparia', but variability was high and differences only occurred in the week 6, day 1 controls (Fig. 9). Comparisons within genotype of control vs. drought-treated plants on week 5 , day 1 and week 6 , day 1 revealed no differences $(P=0.092$ to 0.925$)$.

HaRvest measures. Leaf area at harvest is presented in Table 1, and was strongly correlated with dry shoot biomass (correlation coefficient $=0.964, P<0.001$ ). . Final leaf area for controls was similar in '101-14Mgt', 'Riparia' and '110R', but 'Ramsey' was $45 \%$ lower on average. This difference was less pronounced in drought-treated plants, where 'Ramsey' was $26 \%$ lower (Table 1). 'Ramsey' had a final leaf area that was the least impacted by the drought treatment, with an average value $85 \%$ of that observed in controls, compared with $57 \%$ to $67 \%$ in the other rootstocks. Root biomass trends were similar to leaf area, except that 'Ramsey' root biomass was essentially unchanged in the drought treatment relative to the control (Table 1). In the controls, genotype-based differences in root biomass allocation to the upper and lower soil profile did not sort according to the rank order of root distributions seen in Fig. 3, but drought-treated plants corresponded perfectly (Table 1).

\section{Discussion}

A growing body of work has been published using Vitis species and hybrid rootstocks that characterizes genotypebased differences in traits related to drought tolerance. Most of these studies focused predominantly or exclusively on either the root system (Bauerle et al., 2008; McKenry, 1984; Morano and Kliewer, 1994) or the shoot system (Carbonneau, 1985; Soar et al., 2006; Williams, 2010), but fewer studies (Williams and Smith, 1991) assessed both factors substantively and simultaneously. Although data derived from only the roots or only the shoots have provided valuable insight, it is possible that the relationship between above- and belowground processes may itself prove to be important in better understanding the differences in drought tolerance capacity between genotypes and in efforts to understand this important but complex trait. The use of rhizotron containers (James et al., 1985) provided a practical means by which to quantify some components of this relationship. However, there was uncertainty as to whether traits, especially of root architecture and growth, on very young ( $<3$ months) vines assayed in a greenhouse could be related to the known performance of mature vines in the field.

This experiment measured potentially drought-relevant traits during three distinct periods: prestress, drought stress, and stress recovery. The first of these sought to define constitutive growth patterns that might prevent or delay plant dehydration, whereas the latter two categories measured active plant responses to water stress that might depend on constitutive patterns established prestress. Beginning with the root system analysis, patterns of root growth were found that corresponded to the anticipated rank order of drought resistance. In Fig. 3A, using root intersections with an overlaid grid as an index of root length, a stepwise sequence of increasingly deep root distribution was found beginning with the relatively 


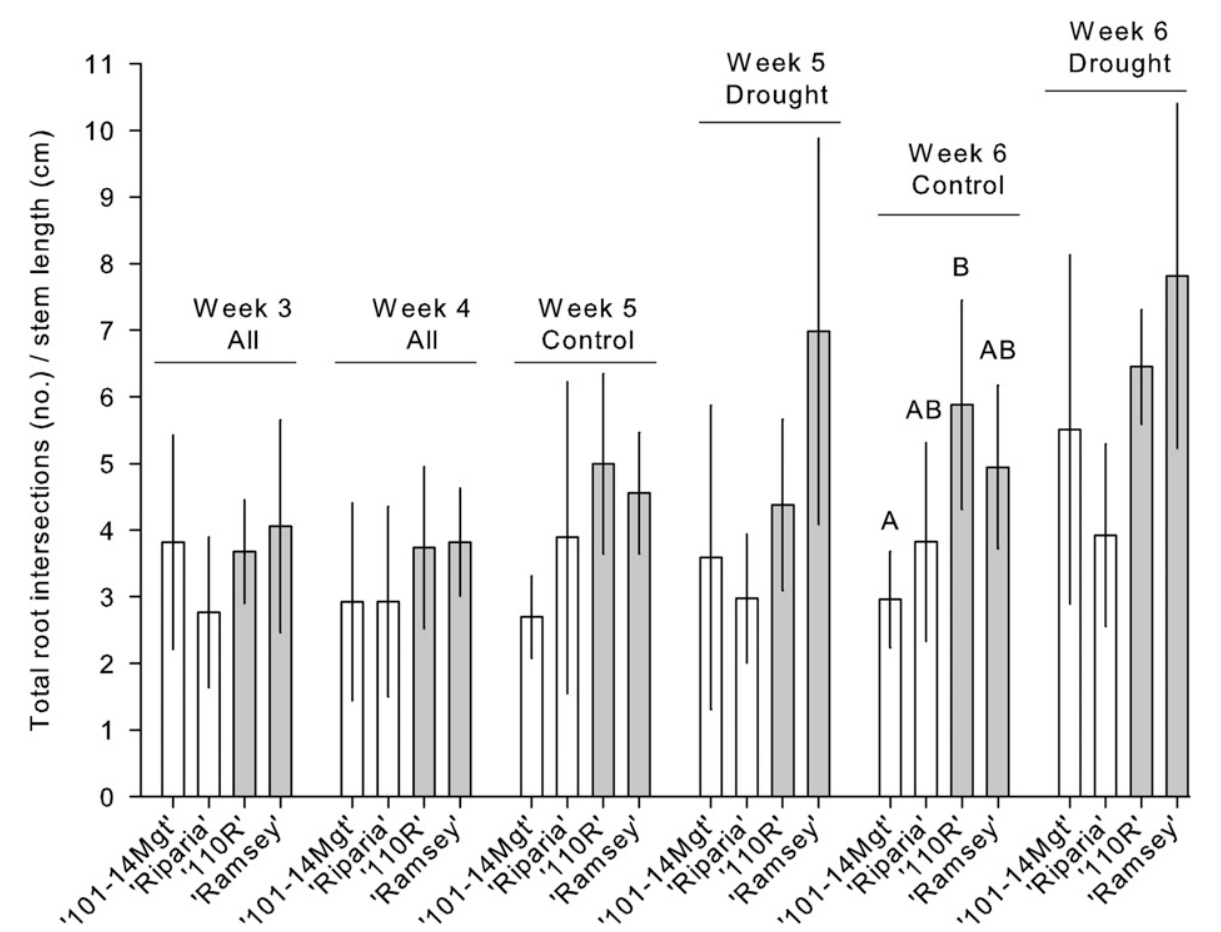

Fig. 9. A 4-week time course of cumulative root growth by total stem length of scions of Vitis vinifera 'Merlot' grafted onto four rootstocks and grown in rhizotron containers. Root measurements were taken on the first day of each indicated week, where week 1, day 1 was the first day of root measurements in the present experiment. Data are cumulative root intersections with an overlaid grid of horizontal lines. Stem length was taken on the same day or within $24 \mathrm{~h}$ of root measurements, except for week 3 where stem length was measured $48 \mathrm{~h}$ prior. Putative drought-resistant rootstocks were noted graphically using gray columns. Drought treatment was imposed from week 4, day 2 to week 4, day 7; therefore, drought-treated and control plants are shown separately for weeks 5 to 6 . Error bars are $\pm 1 \mathrm{sD}$. Post hoc mean separation categories are provided for week 6 controls, the only treatment and period wherein an analysis of variance was significant at $\alpha=0.05$; '101-14Mgt' = 'Millardet et de Grasset 101-14', 'Riparia' = 'Riparia Gloire de Montpellier', and '110R' = 'Richter 110'.

Table 1. Measures of biomass allocation collected at harvest for Vitis vinifera 'Merlot' grafted onto four rootstocks and grown in rhizotron containers, following a 6-d drought treatment and 7-d recovery period.

\begin{tabular}{|c|c|c|c|c|c|c|c|c|}
\hline \multirow[b]{2}{*}{ Rootstock $^{z}$} & \multicolumn{3}{|c|}{ Leaf area $\left(\mathrm{cm}^{2}\right)$} & \multicolumn{3}{|c|}{ Root dry biomass (g) } & \multicolumn{2}{|c|}{ Lower/upper ${ }^{\mathrm{x}}$} \\
\hline & Control & Drought & $\mathrm{D} / \mathrm{C}^{\mathrm{y}}$ & Control & Drought & $\mathrm{D} / \mathrm{C}$ & Control & Drought \\
\hline '101-14Mgt' & $1,425 \mathrm{~A}^{\mathrm{w}}$ & 958 & 0.67 & $3.08 \mathrm{~A}$ & 1.29 & 0.42 & 0.38 & 0.27 \\
\hline 'Riparia' & $1,372 \mathrm{~A}$ & 919 & 0.67 & $1.88 \mathrm{AB}$ & 1.50 & 0.80 & 0.31 & 0.32 \\
\hline '110R' & $1,572 \mathrm{~A}$ & 895 & 0.57 & $2.31 \mathrm{~A}$ & 1.45 & 0.63 & 0.45 & 0.52 \\
\hline 'Ramsey' & $\begin{array}{c}806 \text { B } \\
P=0.01\end{array}$ & $\begin{array}{c}685 \\
P=0.32\end{array}$ & 0.85 & $\begin{array}{l}0.82 \mathrm{~B} \\
P=0.01\end{array}$ & $\begin{array}{c}0.84 \\
P=0.38\end{array}$ & 1.02 & 0.39 & 0.76 \\
\hline
\end{tabular}

$\overline{\mathrm{z}}$ 101-14Mgt' = 'Millardet et de Grasset 101-14', 'Riparia' = 'Riparia Gloire de Montpellier', and ' $110 \mathrm{R}$ ' = 'Richter 110 '.

${ }^{\mathrm{y}}$ Drought value divided by control value.

${ }^{\mathrm{x}}$ Root dry biomass in the lower half of the soil profile divided by that in the upper half.

${ }^{\text {w}}$ Post hoc mean separation categories are provided when an analysis of variance was significant at $\alpha=0.05$.

shallow root distribution of '101-14Mgt' and progressing to the relatively deep distribution of 'Ramsey'. However, these distributions did not fall into four highly distinct categories, although the extreme genotypes '101-14Mgt' and 'Ramsey' were different (Fig. 3B). Incorporating the root angle relative to the soil media surface at each root intersection was intended to improve the root architecture characterization by indicating the directional trend of a root in addition to merely scoring its presence. The most efficient application of this principle was found to be a scoring of only those roots angled sharply downward, arbitrarily defined as $>30^{\circ}$. This analysis resulted in a rank order parallel to that of rooting depth seen in Fig. $3 \mathrm{~A}$, but showed a markedly higher percentage of deeply angled roots in 'Ramsey' relative to the other three rootstock genotypes (Fig. 3C). These results agree with observations from as early as 1905 (Guillon) that noted the shallow angle of emergence of 'Riparia' roots from dormant cuttings and deeper angles from non-'Riparia' genotypes. Studies of plant allometry (Schenk and Jackson, 2002a, 2002b) confirm that relatively deeper root distributions are often found in more arid environments when canopy size is held constant. Nevertheless, simple, strong, and consistent generalizations could not be made within Vitis when the literature was exhaustively reviewed in 2006 (Smart et al.), and it was concluded by these authors that factors outside root distribution should be considered in studies of drought tolerance.

Total root length without reference to root distribution was also investigated as a potential correlate with drought tolerance, but no correspondence to anticipated drought tolerance was found. 'Ramsey' produced about half the number of root intersections as ' $110 \mathrm{R}$ ', and intermediate values were observed in '101-14Mgt' and 'Riparia' (see the Results). Because total rooting volume (and presumably, total root length) correlates positively with aboveground plant volume (Schenk and Jackson, 2002b), it is unsurprising that total root length could not be used as a simple positive correlate of drought tolerance in this study, given the relatively rapid development of the shoot system by the most drought-sensitive rootstock, '101$14 \mathrm{Mgt}$ ', and the relatively slow rate of shoot system development by 'Ramsey' (Fig. 4). The rate of shoot system development observed in this study is likely itself a trait relevant to drought tolerance, as slow growth has long been noted to be a hallmark of abiotic stress resistance (Chapin, 1991). The slow growth of the 'Ramsey' shoot system in young vines may reflect a favorable above- to below-ground allometry that, given sufficient developmental time, will produce a relatively large root system that would contribute to dehydration resistance. Larger and denser root systems in 'Ramsey' were, in fact, found when compared with 
Table 2. Summary of drought-related traits from the present study, which used Vitis vinifera 'Merlot' grafted onto four rootstocks and grown in rhizotron containers.

\begin{tabular}{lllcccc}
\hline Rootstock & $\begin{array}{l}\text { Anticipated } \\
\text { performance }\end{array}$ & $\begin{array}{c}\text { Root } \\
\text { distribution }\end{array}$ & $\begin{array}{c}\text { Shoot growth rate } \\
\text { before drought stress }\end{array}$ & $\begin{array}{c}\text { New root production } \\
\text { during drought }\end{array}$ & $\begin{array}{c}\text { New root production } \\
\text { during recovery }\end{array}$ & $g_{\mathrm{S}}$ during recovery \\
\hline '101-14Mgt' & Susceptible & Very shallow & Fast & Decline & Fast & Low \\
'Riparia' & Susceptible & Shallow & Moderate & Decline & Moderate \\
'110R' & Resistant & Deep & Moderate & Maintained & Moderate \\
'Ramsey' & Very resistant & Very deep & Slow & Maintained & Slow & Moderate \\
\hline
\end{tabular}

$\overline{\mathrm{z}}$ ‘101-14Mgt' = 'Millardet et de Grasset 101-14', 'Riparia' = 'Riparia Gloire de Montpellier', and '110R' = 'Richter 110'.

own-rooted Thompson Seedless in 8- to 17-year-old vines (McKenry, 1984; Nagarajah, 1987).

It was possible that more definitive measures of drought tolerance might be found during a period of water stress. Four days without irrigation in non-'Ramsey' rootstocks and $5 \mathrm{~d}$ without irrigation in 'Ramsey', brought $g_{\mathrm{S}}$ values to low levels compared with daily watered controls (Fig. 7). During this period, stem length was halted in the stress treatment for all rootstocks while control plants had measurable growth (Fig. 6). Restriction of canopy development is known to be one of the earliest measurable responses to water stress (Bradford and Hsiao, 1982); however, rootstocks could not be differentiated using this measure. It is possible that stem length was too crude of a nondestructive index for total leaf area, and a more precise index of this variable, as measured in Alves and Setter (2000, 2004), might have delineated rootstock-specific differences. Alternatively, $g_{\mathrm{S}}$ did reveal such differences. Pooling the values of $g_{\mathrm{S}}$ for drought-stressed plants during the period when all treatment rootstocks were unambiguously lower than daily watered controls (i.e., week 4 , day 6 to week 5 , day 1 ) produced a rank order that corresponded to expected drought tolerance (Fig. 8A). Although not quantified, it was also observed that during this period only ' $101-14 \mathrm{Mgt}$ ' exhibited a small amount of shoot tip necrosis, $<1 \mathrm{~cm}$ in a $<10 \%$ subset of shoot tips. New root growth during the drought period was the only variable measured in this study that distinctly separated '101-14Mgt' and 'Riparia' from '110R' and 'Ramsey' as drought sensitive and tolerant, respectively. For both '101-14Mgt' and 'Riparia', a repeated measures analysis revealed a decline in new root intersections during the drought period for drought-treated plants, but no change in new root production for ' $110 \mathrm{R}$ ' and 'Ramsey' (Fig. 5). These data are similar to results from a field study comparing 11-year-old vines of '101-14Mgt' and 'Paulsen 1103', the latter regarded as drought tolerant (Ollat et al., 2015) and with the same species parentage as '110R' ( $V$. berlandieri $\times V$. rupestris). In that field study, '101-14Mgt' produced about half as much new root length as that produced by 'Paulsen 1103' over three dry summer months, but produced about triple the quantity of new root length during three relatively mesic winter months (Bauerle et al., 2008).

Compared with $g_{\mathrm{S}}$ during drought stress, a more sensitive measure of drought tolerance appears to occur during the onset of recovery from drought, when the drought-tolerant rootstocks showed higher mean $g_{\mathrm{S}}$. When the values for droughttreated plants were pooled for week 5, day 2 to week 5 , day 4 , a rank order was established that corresponded to expected drought tolerance (Fig. 8B). A similar pattern was observed when $g_{\mathrm{S}}$ was expressed as the difference between daily watered controls and drought-treated plants (Fig. 8D), rather than the quantification of drought-treated plants alone (Fig. $8 \mathrm{~B})$. Effective separation of genotypes may be most prominent near the time that stress is relieved, as pooling the data for $6 \mathrm{~d}$ of recovery did not change the rank order but did result in a loss of significance (Fig. 8C). Blum (2011) noted that crop breeding for improved dehydration resistance is more effectively accomplished using shoot-based measures due to the resource intensity of measuring roots. Stomatal conductance, specifically during recovery, may provide such a measure for the evaluation of grape rootstocks. Although not tested in this study, the use of leaf temperature as an even more time-efficient index for leaf water status is now a routine practice (Pask et al., 2012). An infrared thermometer or camera used during the initial days of recovery from drought stress could increase the time efficiency of screening. Finally, new root production during the recovery period increased $(P \leq 0.031)$ for all rootstocks except 'Ramsey' compared with the preceding drought week, and in a rank order that corresponded to prestress shoot growth (Figs. 4 and 5). These results correspond to the results of a similar study using mesophytic and xerophytic wildland species under resource stress and recovery regimes, wherein rates of root and leaf growth after release from stress were highest for the mesophytic species (Espeleta and Donovan, 2002). These authors attributed the faster leaf and root growth rates of the mesophyte Quercus marilandica to selection that maximized resource uptake in a resource-rich soil, but at the cost of reduced stress tolerance, sufficient to contribute to a differential ecological distribution distinct from the xerophyte Quercus laevis.

Table 1 describes several destructive measures taken at harvest following the recovery period. For the final leaf area, it was notable that 'Ramsey' had both the lowest leaf area in the well-watered controls and the smallest difference between the control and drought treatment. Mean leaf area in droughttreated plants increased in rank order from 'Ramsey' to '101$14 \mathrm{Mgt}$ ' as observed in prestress shoot growth. Dry root biomass again showed the lowest value for 'Ramsey' in the control, and nearly identical values in the control and drought treatment. In contrast, root biomass was lower in the drought treatment compared with controls for all non-'Ramsey' rootstocks. The ratio of root biomass in the lower half of the root profile per unit of biomass in the upper half was highest for drought-treated 'Ramsey' and followed a 'Ramsey' to '101-14Mgt' rank order, but this order was not found in the control plants.

It might seem intuitive that a high $\mathrm{R}: \mathrm{S}$ would correlate with increased drought tolerance. In contrast, Blum (2005) asserted that neither dry biomass of roots nor the dry R:S is useful in selection for improved drought tolerance. However, because the R:S changes with time and is influenced by environmental factors, it is unclear at what developmental stage and under what conditions differences would be maximized if they existed. In this study, a nondestructive estimate of R:S was examined over 4 weeks using total root intersections per unit of shoot length. In all weeks and conditions (i.e., both control and 
treatment) beginning in week 4, the mean of the estimate of R:S was higher for ' $110 \mathrm{R}$ ' and 'Ramsey' compared with 'Riparia' and '101-14Mgt' (Fig. 9), but the measured differences were small, and significance was observed only for the control on week 6 , day 1 . If there is any biological significance for this measure that relates to drought tolerance, it might require replication far in excess of that used in this study.

\section{Conclusions}

Table 2 summarizes five traits relevant to drought tolerance capacity found in this study based on their correspondence to the known performance of mature grapevines examined under field conditions. At least one useful trait was found in each of the three distinct phases of this experiment, namely prestress, stress, and recovery. In all of these variables except that observed in new root production during drought stress, stepwise gradations of mean values were found between the rootstocks and with overlapping variability. No single measure stood out as a superior means of distinguishing rootstock genotypes, although the potential to rapidly measure $g_{S}$ during drought stress recovery directly with porometry or indirectly with thermometry or thermography holds promise and warrants further investigation. When measurement efficiency is not considered, the mostly equivalent utility of different biological measures to assess drought tolerance capacity attests to the multifactorial nature of this trait, and under ideal conditions multiple facets of drought tolerance would be measured to ensure robust assessments.

\section{Literature Cited}

Alves, A.A. and T.L. Setter. 2000. Response of cassava to water deficit: Leaf area growth and abscisic acid. Crop Sci. 40:131-137.

Alves, A.A. and T.L. Setter. 2004. Response of cassava leaf area expansion to water deficit: Cell proliferation, cell expansion and delayed development. Ann. Bot. (Lond.) 94:605-613.

Bauerle, T.L., D.R. Smart, W.L. Bauerle, C. Stockert, and D.M. Eissenstat. 2008. Root foraging in response to heterogeneous soil moisture in two grapevines that differ in potential growth rate. New Phytol. 179:857-866.

Blum, A. 2005. Drought resistance, water-use efficiency, and yield potential-Are they compatible, dissonant, or mutually exclusive? Crop Pasture Sci. 56:1159-1168.

Blum, A. 2011. Plant breeding for water-limited environments. Springer, New York, NY.

Bradford, K. and T. Hsiao. 1982. Physiological responses to moderate water stress, p. 263-324. In: O.L. Lange, P.S. Nobel, C.B. Osmond, and H. Ziegler (eds.). Physiological plant ecology II: Water relations and carbon assimilation. Springer-Verlag, Berlin, Germany.

Carbonneau, A. 1985. The early selection of grapevine rootstocks for resistance to drought conditions. Amer. J. Enol. Viticult. 36:195198.

Chapin, F.S. 1991. Integrated responses of plants to stress. Bioscience 41:29-36.

Cirami, R.M. and M.G. McCarthy. 1988. Rootstock evaluation in South Australia, p. 45-47. In: R.E. Smart, R.J. Thornton, S.B. Rodriguez, and J.E. Young (eds.). Proc. Second Intl. Symp. Cool Climate Viticult. Oenol. N.Z. Soc. Viticult. Oenol., Auckland, New Zealand.

de Castella, F. 1935. Phylloxera-resistant vine stocks. J. Dept. Agr. Victoria 33:281-288, 303.

Di Liberto, T. 2015. NOAA Climate.gov: Science \& information for a climate-smart nation. 20 June 2016. <https://www.climate.gov/ news-features/event-tracker/how-deep-precipitation-holecalifornia>.

Dry, P. and B. Coombe. 2005. Viticulture. Volume 1-Resources. Winetitles, Adelaide, Australia.

Espeleta, J. and L. Donovan. 2002. Fine root demography and morphology in response to soil resources availability among xeric and mesic sandhill tree species. Funct. Ecol. 16:113-121.

Fishman, C. 2012. The big thirst: The secret life and turbulent future of water. Simon Schuster, New York, NY.

Galet, P. 1998. Grape varieties and rootstock varieties. Oenoplurimédia, Chaintré, France.

Guillon, J.M. 1905. Étude générale de la vigne: Historique les vignobles et les crus anatomie et physiologie, sol et climat. Masson, Paris, France.

James, B., R. Bartlett, and J. Amadon. 1985. A root observation and sampling chamber (rhizotron) for pot studies. Plant Soil 85:291-293.

Keller, M. 2015. The science of grapevines: Anatomy and physiology. Academic Press, Burlington, MA.

Kerridge, G. and A.J. Antcliff. 1999. Wine grape varieties. CSIRO Publ., Collingwood, Australia.

Kim, J., A. Malladi, and M.W. van Iersel. 2012. Physiological and molecular responses to drought in petunia: The importance of stress severity. J. Expt. Bot. 63:6335-6345.

Lambert, J., M. Anderson, and J. Wolpert. 2008. Vineyard nutrient needs vary with rootstocks and soils. Calif. Agr. 62(4):202-207.

McCarthy, M., R. Cirami, and D. Furkaliev. 1997. Rootstock response of Shiraz (Vitis vinifera) grapevines to dry and drip-irrigated conditions. Austral. J. Grape Wine Res. 3:95-98.

McKenry, M.V. 1984. Grape root phenology relative to control of parasitic nematodes. Amer. J. Enol. Viticult. 35:206-211.

Morano, L. and W.M. Kliewer. 1994. Root distribution of three grapevine rootstocks grafted to Cabernet Sauvignon grown on a very gravelly clay loam soil in Oakville, California. Amer. J. Enol. Viticult. 45:345-348.

Nagarajah, S. 1987. Effects of soil texture on the rooting patterns of Thompson Seedless vines on own roots and on Ramsey rootstock in irrigated vineyards. Amer. J. Enol. Viticult. 38:54-59.

Natali, S., C. Xiloyannis, and M. Castagneto. 1985. Effect of soil water content on leaf water potential and stomatal resistance of grapevine (Vitis vinifera) grafted on different rootstocks. Acta Hort. 171:331-340.

National Climate Centre. 2010. Special climate statement 22: Australia's wettest September on record but it is not enough to clear longterm rainfall deficits. Bur. Meteorol., Melbourne, Australia.

Nemali, K.S. and M.W. van Iersel. 2008. Physiological responses to different substrate water contents: Screening for high water-use efficiency in bedding plants. J. Amer. Soc. Hort. Sci. 133:333-340.

Ollat, N., A. Peccoux, D. Papura, D. Esmenjaud, E. Marguerit, J.-P. Tandonnet, L. Bordenave, S.J. Cookson, F. Barrieu, L. Rossdeutsch, J. Lecourt, V. Lauvergeat, P. Vivin, P.-F. Bert, and S. Delrot. 2015. Rootstocks as a component of adaptation to environment, p. 68-108. In: H. Gerós, M. Manuela Chaves, H. Medrano Gil, and S. Delrot (eds.). Grapevine in a changing environment: A molecular and ecophysiological perspective. Wiley, Chichester, England.

Ordish, G. 1972. The great wine blight. Scribner, New York, NY.

Padgett-Johnson, M., L. Williams, and M.A. Walker. 2003. Vine water relations, gas exchange, and vegetative growth of seventeen Vitis species grown under irrigated and nonirrigated conditions in California. J. Amer. Soc. Hort. Sci. 128:269-276.

Pask, A., J. Pietragalla, D. Mullan, and M. Reynolds. 2012. Physiological breeding II: A field guide to wheat phenotyping. CIMMYT, Mexico, DF.

Pongrácz, D.P. 1983. Rootstocks for grape-vines. David Philip, Cape Town, South Africa.

Pouget, R. and J. Delas. 1989. Le choix des porte-greffes de la vigne pour une production de qualité. Connaisance Vigne et du Vin Hors Série 23:27-31.

Schenk, H.J. and R.B. Jackson. 2002a. The global biogeography of roots. Ecol. Monogr. 72:311-328. 
Schenk, H.J. and R.B. Jackson. 2002b. Rooting depths, lateral root spreads and below-ground/above-ground allometries of plants in water-limited ecosystems. J. Ecol. 90:480-494.

Smart, D.R., E. Schwass, A. Lakso, and L. Morano. 2006. Grapevine rooting patterns: A comprehensive analysis and a review. Amer. J. Enol. Viticult. 57:89-104.

Soar, C.J., P.R. Dry, and B. Loveys. 2006. Scion photosynthesis and leaf gas exchange in Vitis vinifera L. cv. Shiraz: Mediation of rootstock effects via xylem sap ABA. Austral. J. Grape Wine Res. $12: 82-96$.

Southey, J.M. 1992. Grapevine rootstock performance under diverse conditions in South Africa, p. 27-51. In: J.A. Wolpert, M.A. Walker, and E. Weber (eds.). Rootstock seminar: A worldwide perspective. Amer. Soc. Enol. Viticult., Davis, CA.
Stevens, R.M., J.M. Pech, M.R. Gibberd, R.R. Walker, J. Jones, J. Taylor, and P. Nicholas. 2008. Effect of reduced irrigation on growth, yield, ripening rates and water relations of Chardonnay vines grafted to five rootstocks. Austral. J. Grape Wine Res. 14:177-190.

Walker, R. and P. Clingeleffer. 2009. Rootstock attributes and selection for Australian conditions. Austral. Viticult. 13:69-76.

Williams, L. 2010. Interaction of rootstock and applied water amounts at various fractions of estimated evapotranspiration (ETc) on productivity of Cabernet Sauvignon. Austral. J. Grape Wine Res. $16: 434-444$.

Williams, L. and R. Smith. 1991. The effect of rootstock on the partitioning of dry weight, nitrogen and potassium, and root distribution of Cabernet Sauvignon grapevines. Amer. J. Enol. Viticult. 42:118-122. 